\title{
The Usage Behaviors, Motivations and Gratifications of Using User-Generated Media: The Case Study of Taiwan's YouTube
}

\author{
Tai-Li Wang \\ The Graduate Institute of Journalism, National Taiwan University, Taiwan \\ Email: tailiw@ntu.edu.tw
}

Received 12 September 2014; revised 15 October 2014; accepted 18 November 2014

Copyright (C) 2014 by author and Scientific Research Publishing Inc.

This work is licensed under the Creative Commons Attribution International License (CC BY). http://creativecommons.org/licenses/by/4.0/

(c) (i) Open Access

\section{Abstract}

Video sharing websites have become an indispensable online service to Internet users. We aim to investigate the relationships between motivations of using video-sharing websites, online reputation management, innovation orientation, and video-sharing website usage behaviors, and how these factors affect gratification obtained from video-sharing website usage. This study employs focus group interviews and online questionnaire surveys. The research findings reveal that the higher the interpersonal media related motivations, such as participating or sharing, the higher the level of involvement of video-sharing website usage behaviors is. However, the mass media related motivations, such as browsing or consuming, are irrelevant to the level of usage involvement. The earlier users adopt video-sharing websites, the higher level of usage involvement is. The more value video-sharing websites' users put for video sites' performance perception, the lower level of usage involvement is; on the contrary, the more value video-sharing websites' users put for impression management, the higher level of usage involvement is. Taken as a whole, the higher level of usage involvement, the higher level of gratifications acquired from using usergenerated video-sharing websites is. This paper establishes a comprehensive behavior model of video-sharing websites, which is helpful both for online media research and business practice. It is worthy of noting that the findings are based on survey data from a single country, and may impact this paper's external validity.

\section{Keywords}

Diffusion of Innovation, Impression Management, User Generated Media Model (UGM Model), Uses and Gratification, YouTube 


\section{Introduction}

On March 11, 2011 an earthquake triggered a massive tsunami in Japan. The resulting natural disturbances were videotaped by a number of affected residents. Many of these homemade video clips were uploaded to YouTube by Taiwanese netizens to express concern for Japan. Not only did these videos spread rapidly on the Internet, they also caught the attention of the mainstream media. One particular example is "God Bless Japan” (2011). In this video, a netizen inspired others to write the words "God Bless Japan" on their palms. The footage was collated and edited into a clip. The clip attracted over 720 thousand clicks and more than 6 thousand comments in a short period of time. This is one recent event which once again brought attention to the propagation characteristics and the effectiveness of video-sharing websites.

In fact, YouTube has become an indispensable online service to Internet users. A survey reports that the number of people in Taiwan using online video sites in the previous month has increased to 70 percent (iSURVEY, 2010). Globally, there are 183 million users visiting YouTube monthly (Yang, Hsu, \& Tan, 2010). These figures demonstrate the growing popularity of video sites, which have become a vital online medium of the Internet generation.

Despite the rise of online video sites, previous academic research has been primarily on the content genre or function (Harp \& Tremayne, 2007; Ye, 2007), or tends to assume the traditional concept of mass media usage behavior, and takes the simplified view of video site usage as a single Web browsing behavior (Tsai, Tsai, Xie, \& Chen, 2006; Lee, 2008). Some studies do differentiate watching and sharing behaviors, but lack an overall behavioral model of using video sites (Hanson \& Haridakis, 2008; Yang et al., 2010). Moreover, past research also lacked a comprehensive study on users, with the subjects mostly made up of young students (Kao, 2006; Chen, 2008; Courtois, Mechant, Marez, \& Verleye, 2009).

Therefore, one of the most prominent blind spots in past research on video-sharing websites may arise from the definition of video site usage behavior. User-Generated Media (UGM) is a new kind of media, as a user's role is beyond that of a mere user. This paper posits that an encompassing model of user behavior needs to be proposed for the study of video-sharing website usage.

As such, this paper assumes atheoretical UGM model proposed by Shao (2009), which identifies three video site usage behaviors: consuming, participating, and producing, and attempts to substantiate the model by empirical study.

Since past studies did not thoroughly explore the motivations and satisfaction of multiple aspects of production and usage, focus group interviews were first conducted to test the suitability of the UGM model. The results of the interview also aided in the development of the online survey questionnaire for the second phase.

The outcome from the focus group yielded two aspects previously unconsidered aspects, namely reputation management and innovation. It was discovered that many respondents described their retrospective experience in the pursuit of innovative communication technology, and their experiences of managing online impression. In the process, it has been found that their behavior may well be influenced by the Diffusion of Innovation theories. Therefore, this paper applies both the Uses and Gratifications and Diffusion of Innovation perspectives, in order to enhance our prediction on user behavior.

To sum up, the purpose of this paper is to establish an over all behavior model of the usage of user-generated video sites, in order to explore the relationships among the motivations, reputation management, innovation orientations, and user behaviors concerning video sites. This paper further attempt to investigate how these factors affect the gratifications obtained from using video-sharing websites.

\section{Literature Review}

This paper will firstly exam previous studies on user generated media models to explore users' involvement of their video website usage. Then the uses and gratification perspectives and reputation management theories on websites are proposed to sketch this paper's theoretical frameworks. Finally, a few potential demographic factors which may affect users' involvement level in video website usage are discussed in details.

\section{UGM-User Generated Media Model and Users' Involvement Level of Video Website Usage}

User-generated video sites have multiple functions; therefore, users may have to take on multiple roles when using these sites, and these roles need to be distinguished. 
Shao (2009) established a UGM model based on uses and gratification theories. The three video-website usage behaviors of the model are consuming, participating, and producing. Consuming behaviors refer to the individuals who only watch, read, or view for information and entertainment. Participating behaviors include both user-to-user interaction and user-to-content interaction (such as scoring, adding to a playlist, sharing, commenting), primarily for social interaction and community development. Producing behaviors refers to the creation and publication of one's personal work such as text, images, audio, and video, mainly based on self-expression or self-actualization motivations.

These three usages of UGM activity can be analyzed separately, but they also can be viewed as dependent units to suit different needs of users in any combination. Therefore, in addition to separately considering these three types of user's behaviors concerning video-sharing websites, this study considers another significant issue: how these behaviors will be integrated in the Web 2.0 era.

This study suggests that the user behaviors concerning video-sharing websites cannot only be divided into three levels (including browsing, commenting, and producing) upon the levels of involvement, but they are also integrated into a comprehensive "Produsage Behavior" based on users' free will (Bruns, 2008).

When producers and users combined into "produser", the producers and distributors lost their position from the production value chain. Users have become a part of content production, extending the process of creating common information. In this value chain, participants play a dual role as users and producers, and thus becoming “produsers" (Bruns, 2008).

The idea of produsage can be traced back to $80 \mathrm{~s}$. Alvin Toffler (1980) in Third Wave mentioned the concept of prosumer and prosumerism. The consumption pattern of online content is a process of users' gradual involvement. In the process, users' different levels of involvement are caused by different levels of use. The levels of involvement of consuming behavior in video-sharing websites are lower than producing. Regarding this, Toffler (1980) did not distinguish the difference between producing and participating behavior, but took them both as a productive behavior. After the rise of video sites, the concept of Internet content usage involvement has also been used to study video-blog usage behaviors (Örnebring, 2008). The current paper argues that, combining with the concept of Shao's (2009) UGM model and the concept of online video behavior from Toffler (1980) and Bruns (2008), it is better to analyze users' different levels of involvement in using video-sharing websites with the concept of the level of involvement of video-sharing website users' behaviors, for more precise exploration of a comprehensive user's behavior of video-sharing websites.

\section{Uses and Gratification Perspectives}

The centrality of the individual audience member suggests the value of applying audience-centered perspectives to studying media use in an environment in which users can receive, publish, and modify Web content freely. The predominant research framework for studying media use from the audience's perspective is uses and gratifications, which assumes that people use media to satisfy underlying needs.

Proposing uses and gratification, Katz, Blumler, and Gurevitch (1974) hypothesized that audience members are conscious when selecting media, are able to identify their reasons for choosing media, and motives for media use are shaped by audiences' particular social and psychological characteristics. Five major motivations for media uses were proposed out of the social and psychological functions of the mass media: cognitive needs, affective needs, personal integrative needs, social integrative needs, and tension release needs (Katz, Gurevitch, \& Haas, 1973).

The Internet not only blurred the boundaries between mass media and interpersonal communication, but it also combined characteristics of both media (Morris \& Ogan, 1996). The user-generated video site is a medium where users can receive both mass media messages and send interpersonal messages. Therefore, motivations for using video-sharing websites should include motivations of both the traditional mass media and interpersonal communication media.

Prior Internet research has identified both traditional media-related motives, such as for entertainment (Ebersole, 2000; Wolfradt \& Doll, 2001), information (Kaye, 1998; Papacharissi \& Rubin, 2000), passing time, or distraction from boredom (Ebersole, 2000).

For browsing behavior on video-sharing websites, a great amount of content was originated from traditional media, especially from television. The majority of video-sharing website content is about entertainment (InsightXplorer, 2009; iSURVEY, 2010). As a result, the traditional media motivations of entertainment, infor- 
mation, and passing-time should also be motivations for using video-sharing websites.

Therefore, summarizing the perspectives of uses and gratifications theory, the UGM model, and users' involvement with video-sharing websites, this study proposes the first hypothesis:

H1: The motivations for using video-sharing websites will impact the levels of users' involvement in using video-sharing websites.

Because browsing behaviors on video-sharing websites are closer to viewing traditional mass media, this paper further assumes that browsing motivations should be based on entertainment or information-seeking needs, and users require less computer skills or effort than evidenced in participating or producing, thus users may have lower levels of involvement. Therefore, this study proposes that:

H1-1: The higher motivations for browsing video-sharing websites, the lower level of users' involvement with using video-sharing websites.

For commenting behavior on video-sharing websites, this paper posits that motivations related to interpersonal interactions, such as online community participation or belonging, should be closer to the characteristics of interpersonal communication media of video-sharing websites. For example, Baumer, Sueyoshi, and Tomlinson (2008) found that blog readers regard themselves as participants of a blog, rather than merely luring outsiders; moreover, community participation or belonging are all important motivations for using blogs. Kaye (2005) also pointed out that the blog is not an immediate interactive space, and among all kinds of interaction, self-expression and personal fulfillment are usually significant motivations (Kaye, 2005).

Because participating is closer to the characteristics of interpersonal communication media, this paper assumes that participating motives should be out of the demand for social interaction or community involvement, and therefore, engage an advanced level of video-sharing website usage behavior. The study assumes that:

H1-2: The higher motivations of commenting on video-sharing websites, the higher level of users' involvement when using video-sharing websites.

For producing behaviors, YouTube users were found to employ various self-presentation strategies to manage their images to expand their online social networks (Chen, 2009). Users produce video content to manage their online image. One of the ultimate goals should be to obtain interpersonal gratification. Huang, Shen, Lin, and Chang (2007) identified the following four motivations: self-expression, life document, commenting, and community forum participation, which lead to interaction-orientation behavior on blogs. Interaction-oriented blogging behavior positively corresponds to the frequency of interacting with other bloggers and managing blogs. This paper assumes that the producing motivation should come from self-presentation and social need, which involve higher levels of video-sharing website usage; therefore, the study establishes:

H1-3: The higher motivations of producing content on video-sharing websites, the higher level of users' involvement with using video-sharing websites.

\section{Diffusion of Innovation}

The Diffusion of Innovation theory proposed that the "innovation-decision process" involves an individual or organization experiencing a series of steps before the innovation is adopted (Rogers, 1983). Rogers (1983) further defined five factors of innovations that influence an individual's decision to adopt or reject an innovation: Relative Advantage, Compatibility, Complexity, Triability, and Observability.

In addition, the Diffusion of Innovation model follows an S curve when plotted over a length of time. Rogers (1983) developed five distinct innovation "adopter categories" to classify individual attitudes towards technology: innovators, early adopters, early majority, late majority, and laggards. Innovators are the first individuals to adopt an innovation, to take risks and experience new ideas in the early adoption stages, and to play important roles in the diffusion process. This paper deems the Diffusion of Innovation model appropriate to investigate the diffusion process of video-sharing websites and their users' behaviors.

Recent Internet studies continually found that users' innovation orientation is positively correlated with the level of their Internet use. The higher the innovation orientation, the higher the Internet adoption level is (Busselle, Reagan, Pinkleton, \& Jackson, 1999).

Oh, Susarla, and Tan (2008) applied the diffusion theory to social networks and found that centrally connected users take on opinion-leader roles in transmitting information, and have a great impact on other users in the spread of new videos. In the context of video-sharing websites, new videos usually do not acquire recognition from the overall users. Opinion leaders in this instance could promote new videos in the early stages of dif- 
fusion.

To summarize, a video-sharing website's innovative characteristics should include relative advantage, trust, interface, and perceived critical mass. The earlier adopters of video-sharing websites should present stronger characteristics of innovation, and demonstrate higher levels of involvement with video-sharing website usage. Therefore, this study proposed the second hypothesis:

H2: Innovation orientation will be positively related to the level of involvement of video-sharing usage behaviors.

H2-1: The higher the innovation orientation of video-sharing websites' users, the higher level of involvement with the usage.

H2-2: The earlier adopters use video-sharing websites, the higher level of involvement with the usage.

\section{Reputation Management: Site Performance and Impression Management}

Video-sharing websites combine the characteristics of interpersonal and mass media. In terms of interpersonal media, the concept of "impression management" or "self-presentation" is closely related to usage behavior. As for the characteristics of the mass media, user behavior is closely related to a user's perception or satisfaction of video-sharing websites' performance. Taken together, users' perceptions of site performance and their impression management on the site could be theorized as reputation management of video-sharing websites.

The self-presentation concept, also referred to as impression management, was originally developed to explain that every individual performs a certain role while appearing in public. Goffman (1959: p. 17) explained it as "the ways individuals manage impressions of themselves on their audiences". Every individual's presentation in a socially interactive scene has some specific meaning; therefore, the process of controlling the formation of others' impressions is called impression management. Leary and Kowalski (1990) proposed that impression construction involved two processes: determining the type of impression one tries to make and choosing how one goes about it. This study conceptualizes impression management on video-sharing websites in accordance with scholars who have defined self presentation in terms of fostering an impression others hold of them.

The Internet enables people to develop and strengthen their interpersonal relationships, which not only provides opportunities for self presentation, but also provides new challenges. Although self presentation takes place offline as well, self-presentation online is much more manageable than it is offline because it is convenient for users to create, modify, and edit messages about themselves (Walther \& Burgoon, 1992).

In this respect, participating or producing behaviors on video-sharing websites is relevant to strategic impression management because users periodically updated their personal video archives (in order to establish their ideal online identities) and frequently obtain comments from visitors (being validated by other people).

Visitors' participation affects the level of online users' impression management; users are encouraged to selfdisclose more and to please other browsers if they have more visitors. Consistent with what Schlenker and Wowra (2003) argued, in the interactive process, individuals know what their external behavior shows, and that the behavior will lead others to evaluate them.

Another dimension of reputation management on video-sharing websites is the sites' performance, that is, user's perceptions of browsing video-sharing websites. Previous studies of users' perceptions of Websites usually focused on satisfaction of the sites (McKinney, Yoon, \& Zahedi, 2002; Melone, 1989; Tsai, 2007) and investigated users' satisfaction along the dimensions of site designs, system functions, information content, and interaction (Ye, 2007). These dimensions were closely related to users' browsing behaviors, and greatly affect users' continuous uses of video-sharing websites.

Therefore, the third hypothesis is proposed:

H3: Reputation management will affect the level of involvement in video-sharing website usage.

H3-1: The more important users value the sites' performances, the lower level of usage involvement.

H3-2: The more important users value the reputation management, the higher level of usage involvement.

\section{Demographics and the Users' Involvement Level in Video Website Usage}

The relationship between new computer technology development and demographic characteristics has attracted a significant amount of academic attention. Studies constantly revealed that male users outnumbered females, and they had higher tendency of Internet addiction. It also found that the stronger the Internet usage motives, the higher the levels of Internet gratification (Hsiao, 1998). Studies on home computers or electronic newspapers 
both showed that the adopters of new technologies tend to be male, better educated, and had higher personal income (Dutton, Rogers, \& Jun, 1987; Li, 2003). Young and male users were more likely to show higher selfefficacy in computers and locus of control (Broos \& Roe, 2006).

However, studies on video-sharing websites emerged divergent results. Younger and lower-educated users were positively correlated to the entertainment uses of video-sharing websites (Peter \& Valkenburg, 2006). A Finnish study on teenagers showed that lower-educated users had a higher likelihood to produce video online; younger users are also more likely to participate than to produce. Compared with male users, female users participate and produce more on sites (Courtois, Mechant, Marez, \& Verleye, 2009).

Chen (2008) found that age and educational levels were not significantly related to content creators on video websites. Content creation may be due to users' professional knowledge of editing software required to produce online content, regardless of educational levels.

As Livingstone \& Bober (2005) emphasized, the Internet population has been ushered into the age of heterogeneity, and demographic characteristics will not last forever. As video-sharing websites are used for entertainment around the world, this study suggests that the level of education may not a determining factor affecting video-sharing websites' uses. However, based on users' demographic characteristics of video-sharing websites, we suggest that the males are more likely to have higher involvement in video-sharing website usage than females.

Therefore, the forth hypothesis is proposed:

H4: Male users will have higher levels of involvement with video-sharing website usage than female users.

Finally, the original hypothesis of the uses and gratifications theory proposed that audience members consciously select media to meet their psychological needs. Empirical studies also confirmed that stronger motivations for Internet use would lead to obtaining stronger gratification (Hsiao, 1998; Kaye, 1998; Charney \& Greenberg, 2002; Song, LaRose, Eastin, \& Lin, 2004).

Therefore, the final hypothesis is proposed:

H5: The higher level of involvement with video-sharing Web site usage, the higher level of gratification will be acquired from video-sharing Websites.

The conceptual model is illustrated in Figure 1.

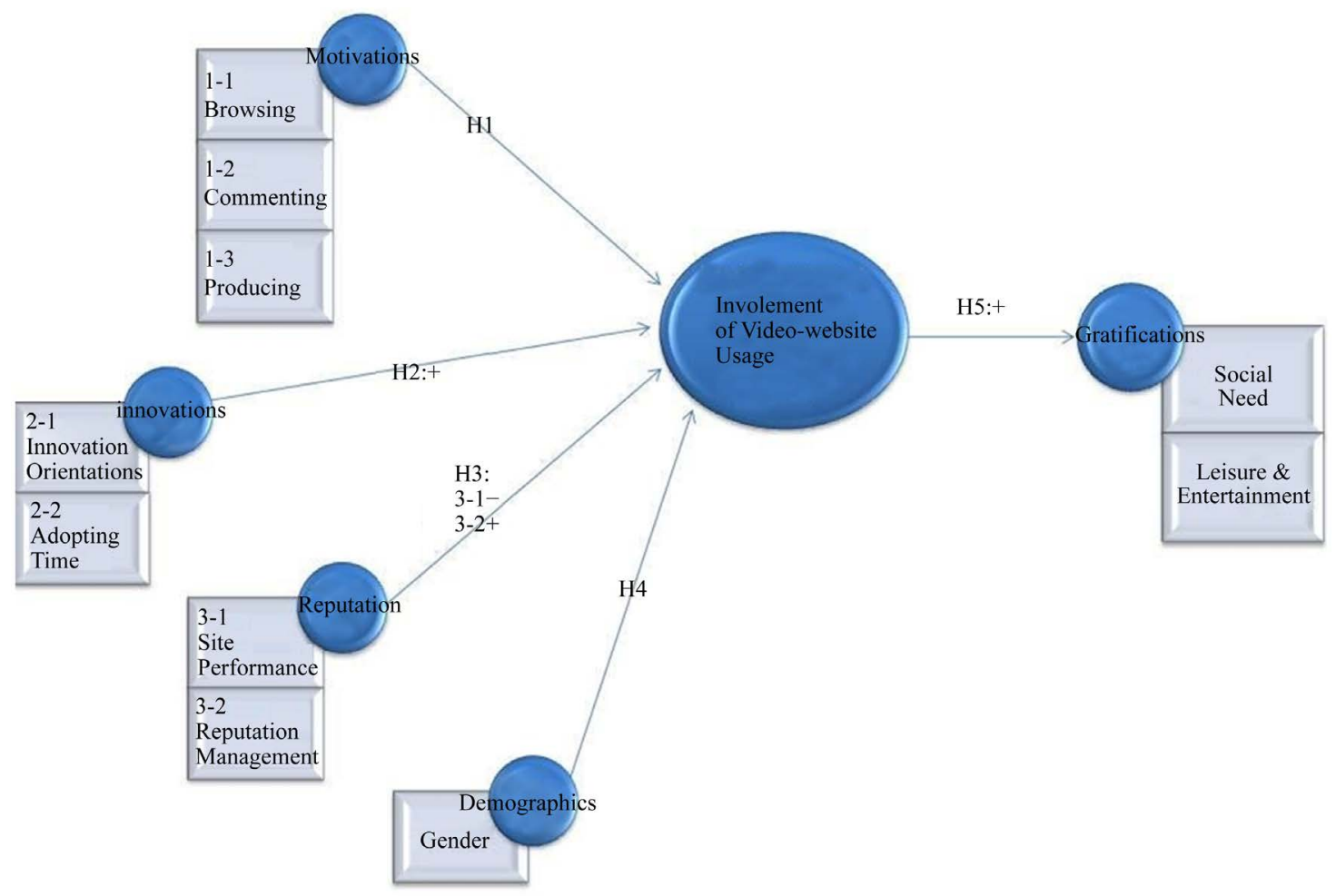

Figure 1. Conceptual model of UGM usage behavior. 


\section{Method}

This study first obtained user's experiences and opinions from 4 focus group interviews. Based on both the literature and interview findings, we designed a questionnaire for online surveys. The question items are listed in Table 1.

The questionnaire includes variables of motivations for using video-sharing websites, innovation orientations, site performance, reputation management, gratifications, and demographics. Except demographic variables, all other items are measured on 6-point Likert scales from strongly disagree, disagree, slightly disagree, slightly agree, and agree, to strongly agree.

The primary variables are measured and defined as follows:

1) Motivations: There are seven browsing motivation-related items; two factors were extracted as "Seeking Information" and "Entertainment”; nine items were composed of commenting motivations, and "Interpersonal Interaction” and "Recommendation” were extracted; nine items of producing motivations, "Recording \& Sharing Life" and "Self-Expression” were extracted.

2) Involvement of UGM: Involvement of video-sharing website usage distinguishes user-generated behavior into four levels, from the lowest-level "browsing only”, "browsing and commenting”, "browsing and producing”, and finally the most high-end "browsing, commenting, and producing".

3) Gratifications: The gratifications were obtained from the experience of using video-sharing websites; two factors were extracted from the eight survey items: "Social Need” and "Leisure \& Entertainment".

4) Innovation Orientations: Three factors were extracted from fifteen items of the users' characteristics and tendencies of innovations: “Popularity \& Fun”, “Adventure \& Excitement”, and “Convenience \& Advantage”.

5) Adoption Time of Video-Sharing Website Technology: Users were divided into five categories, including innovators, early adopters, early majority, later adopters, and laggards.

6) Site Performance: Aimed to understand how much users value the quality, speed, content choices, and content updating rate of video-sharing websites.

7) Reputation Management: Aimed to understand how much users value friends' or relatives' evaluations of their work, messages, or comment management, and how such feedback affect their work afterwards.

8) Demographics: Gender.

The formal online survey was held from June 18 to June 24, 2010 in Taiwan. There were 5800 respondents randomly selected from the member list of an Internet survey company. Survey links were sent to them, and 2173 respondents clicked the link, resulting in a participation rate of 37 percent. Among them, 108 were halfway out and 520 were unable to respond because of quota limits. After data clear-up, 950 samples were retained from 1114 valid samples.

The demographic information of the 950 qualified samples is as follows: Male respondents (51.4 percent) slightly outnumbered female respondents (48.6 percent). Respondents aged 20 to 29 years made up the greatest number of respondents (29.9 percent), followed by 30 to 39 years (27.9 percent), and 40 to 49 (18.3 percent), aged 19 and below (16.9 percent), and aged 50 and over (6.9 percent). The university education level accounts for 44.0 percent, followed by high school (24.1 percent).

The 950 respondents all had browsing experience, including 237 respondents (24.9 percent) had commenting experience, and 198 respondents (20.8 percent) had producing experience. The top three commonly browsed video contents are Entertainment \& Sports (80.9 percent), Information \& Learning (12.2 percent), and Life Document (6.9 percent).

Reliability analysis is used to examine the validity of the questionnaire. There were 59 items examined, and the Cronbach $\alpha$ values ranged between .825 to .903 with an average of o.864. KMO values range from .801 to .913 , which is above a .70 statistical level, and the Bartlett test value is significant $(p<.001)$. Therefore, all items are suitable for factor analysis.

Principal component analysis and Varimax rotation were used for factor analysis. Table 1 indicates the findings. Factor loadings of each factor are above .483, greater than the standard value of .3, and the explained variances of each factor are between 55.26 to 72.83 percent.

\section{Analysis and Results}

This study applied path analysis to investigate the relationship between variables. The first hypothesis predicted that those who have higher motivations of browsing video-sharing websites will have higher levels of involve- 
Table 1. Cronbach alpha of factors.

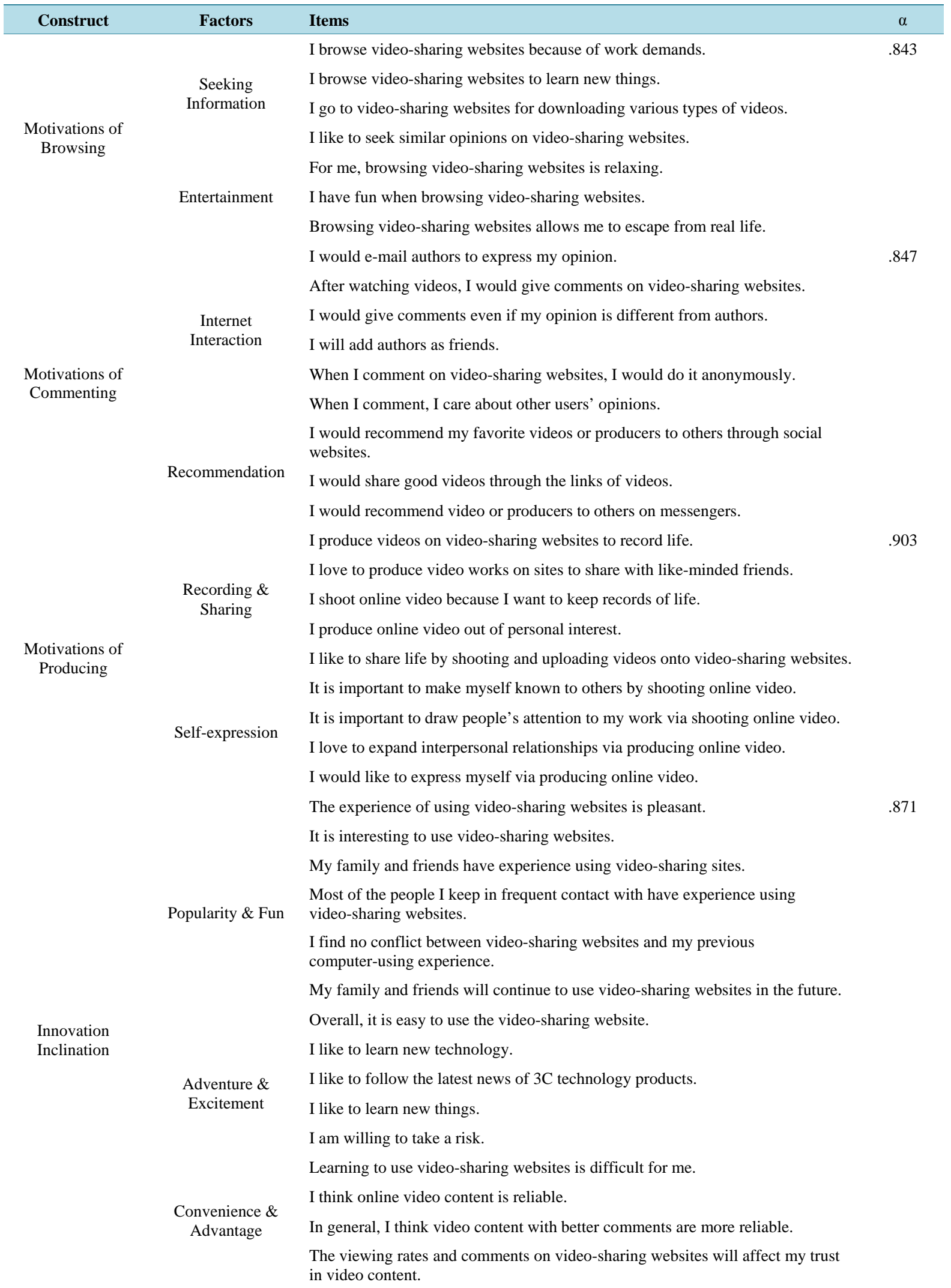




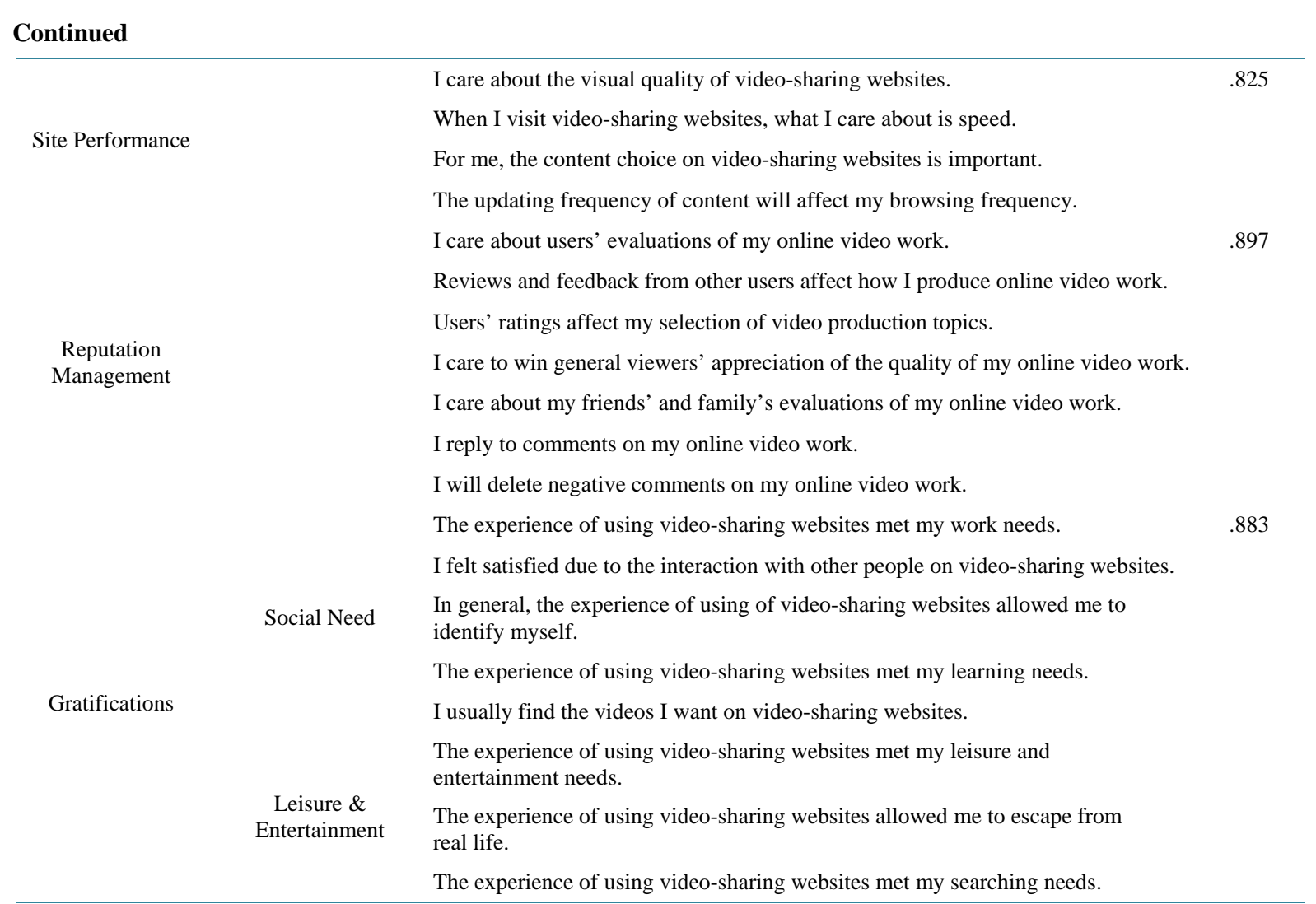

ment with video website usage. The path analysis showed that two factors of browsing video-sharing websites, “Seeking Information" ( $\beta=.01, p=.15)$, and "Entertainment" did not significantly affect users' involvement levels of video website usage $(\beta=.00, p=.98)$. Hypothesis $1-1$ is not supported. Table 2 summarizes the research findings.

For Hypothesis 1-2, two factors of commenting motivation, "Internet Interaction" ( $\beta=.14, p<.001)$ and "Recommendation" $(\beta=.28, p<.001)$, both significantly affected users' levels of involvement of video website usage. Therefore, Hypothesis $1-2$ is supported.

For Hypothesis $1-3$, while "Recording \& Sharing” $(\beta=.68, p<.001)$ had a significant impact on users' involvement, "Self-Expression" ( $\beta=-.04, p=.21)$ did not have such effect. Therefore, Hypothesis $1-3$ is partially supported.

Hypothesis 2-1 predicted that those who have higher innovation orientations will have higher levels of involvement with video website usage. However, three factors of innovation orientations, "Popularity \& Fun" ( $\beta=$ $-.03, p<.05)$, "Adventure \& Excitement" $(\beta=-.02, p<.05)$, and "Convenience \& Advantage" $(\beta=-.02, p$ $<.05$ ) have significant but negative effects on users' levels of involvement with video website usage. Therefore, Hypothesis 2-1 is not supported.

Hypothesis 2-2 predicted that those who adopt video-sharing website technology earlier will have higher levels of involvement with video website usage. Results confirmed that the adopting time has significant and positive effects on users' levels of involvement with video website usage $(\beta=.15, p<.001)$, Hypothesis $2-2$ is supported.

The third hypothesis predicted that reputation management will affect users' levels of involvement of videosharing website usage. For Hypothesis $3-1$, the performances of the sites $(\beta=-.02, p<.05)$ did lead to lower level of users' involvement with video website usage. Hypothesis 3-1 is supported. For Hypothesis 3-2, reputation management $(\beta=.16, p<.001)$ did lead to users' higher level of involvement with video website usage. Hypothesis 3-2 is also supported.

Hypothesis 4 stated that gender will affect users' levels of involvement with video website usage; male users will have higher involvement levels. However, different gender $(\beta=.00, p=.98)$ did not differ in the levels of 
Table 2. Summary of results.

Hypothesis

Hypothesis 1. Higher motivations of to use video-sharing websites will lead to higher levels of users' involvement with video website usage.

Hypothesis 1-1. The higher motivations to browse video-sharing websites, the lower level of involvement with video website usage.

(1) The higher "Seeking Information" motivation to browse video-sharing websites, the lower level of involvement with video website usage.

(2) The higher "Entertainment" motivation to browse video-sharing websites, the lower level of involvement with video website usage.

Hypothesis 1-2. The higher motivations for commenting on video-sharing websites, the higher level of involvement with video website usage.

(1) The higher "Internet Interaction" motivation of commenting video-sharing websites, the higher level of involvement with video website usage.

(2) The higher the "Recommendation" motivation for commenting on video-sharing websites, the higher level of involvement with video website usage.

Hypothesis 1-3. The higher motivations of producing works on video sharing websites, the higher level of users' involvement with video website usage.

(1) The higher "Recording \& Sharing" motivation for producing on video-sharing websites, the higher level of involvement with video website usage.

(2) The higher "Self-Expression" motivation for producing on video-sharing websites, the higher level of involvement with video website usage.

Hypothesis 2. Innovation-orientation will be positively related to users' levels of involvement with video-sharing website usage.

Hypothesis 2-1. The higher users' innovation orientations, the higher levels of involvement with video website usage.

(1) "Popularity \& Fun” will be positively related to levels of usage involvement with video-sharing websites.

(2) “Adventure \& Excitement” will be positively related to levels of usage involvement with video-sharing websites.

(3) "Convenience \& Advantage" will be positively related to levels of usage involvement with video-sharing websites.

Hypothesis 2-2. The earlier users adopt video-sharing websites, the higher levels of their usage involvement.

Hypothesis 3. Reputation Management will affect users' levels of involvement with video-sharing website usage.

Hypothesis 3-1. The more important video-sharing websites' users value the sites' performances, the lower levels of the usage involvement.

Hypothesis 3-2. The more important video-sharing websites' users value the reputation management, the higher levels of the usage involvement.

Hypothesis 4. Gender will affect users' levels of involvement of video-sharing website usage: Male users will have higher levels of involvement than female users.

Hypothesis 5. The higher levels of users' involvement with video-sharing websites' usage, the higher level of gratifications users will acquire from their experience using video-sharing websites.

(1) The higher levels of usage involvement, the higher levels of "Social Needs" gratifications will be acquired from using video-sharing websites.

(2) The higher levels of usage involvement, the higher levels of "Leisure \& Entertainment" gratifications will be acquired from using video-sharing websites.
B coefficient Remark

Partially

Supported

Not

Supported

.01

0

Supported

$.14^{* * * *}$

$.28^{* * *}$

Partially

Supported

$.68^{* * *}$

$-.04$

Partially Supported

Not Supported

$-.03^{* * *}$

$-.02^{* *}$

$-.02^{* *}$

$.15^{* * * *}$

Supported

Supported

$-.02^{*}$

Supported

$.16^{* * *}$

Supported

0

Not

Supported

Supported 
involvement. Hypothesis 4 is not supported.

Finally, Hypothesis 5 proposed that users' higher involvement with video website usage would lead to higher levels of gratification. Results confirmed that users' levels of usage involvement had positive effects on "Social Need" $(\beta=.29, p<.001)$ and "Leisure $\&$ Entertainment" $(\beta=.10, p<.01)$. Hypothesis 5 is supported.

Path analysis confirmed the direct effect of users' involvement with video-sharing websites' usage and gratification. According to the principles of path analysis, we further verify the indirect effect of users' involvement with video-sharing websites' usage and gratification to clarify the relationship between them.

Via the mediation effect of users' levels of involvement with video website usage, we particularly found that the indirect effect $(\beta=.2, p<.001)$ of "Recording \& Sharing" on the "Social Needs" is greater than the direct effect $(\beta=-.012, p<.001)$; therefore, the total effect $(\beta=.188, p<.001)$ turned out to be positively related to "Social Needs". The higher "Recording \& Sharing" motivation for browsing video-sharing websites, the higher level of "Social Needs" gratification acquired from using video-sharing websites. All other independent variables did not impact users' gratification because of the indirect effects.

\section{Research Conclusion and Discussion}

This paper originally hypothesized that the degree of attention or effort required for browsing behavior is lower than that of other UGM behavior; therefore, the greater the browsing motivations, the lower the level of involvement. However, research has shown that these two factors are unrelated. Although in the process of conducting a video search, a certain level of initiative is required, compared to the level of initiative of participating and producing, the passive nature of browsing behavior becomes more apparent. This could be one of the reasons why browser motive is unrelated to the level of involvement.

In relation to participation, the higher the motivations for participation in commenting, regardless of whether the motivation stems from online interaction or a recommendation of a good piece of work, the higher the level of involvement on video sites. Due to the participative and interactive nature of video sites, whether it is commenting or discussing, or even taking the initiative to recommend work, these actions can be considered as social interaction and community involvement. At the same time, they also require one to put in more attention, focus, and time as compared to purely browsing alone. As such, the level of involvement may be higher.

As for producing, it has also been confirmed that the higher the motivation for record-sharing, the higher the level of usage involvement with video sites. It was originally hypothesized that producing and uploading is due to the need to present oneself as well as to establish personal relationships. As such, the level of involvement may be higher. However, the findings show that the motivation for recording-sharing, as a predictive variable on the level of involvement, far exceeds that of self-expression.

In the past, research on predominantly text-based blogs suggests that self-presentation is often a crucial motivational factor. The main focus of this study is video sites that deal primarily with videos or images, and this shift in focus has yielded different results. Haridakis and Hanson (2009) pointed out that "co-viewing" is a unique aspect of video sites, and is distinct from typical text-based blogs. This feature of co-viewing fully reflects the characteristic social linking of the Internet. Rather than stating that video sites are the composites of the mass and interpersonal media, it may be more accurate to view them as a new type of social media (Fernando, 2007). From this perspective, the motive for recording-sharing may indeed be more effective in predicting the level of involvement with video sites than the motive for self-presentation.

With respect to the overall research results, it seems that it is easier to predict video site users' behaviors in using the video site, as compared to interpersonal communications-related motives, such as social interactions, community involvement, and sharing. This finding, together with some past research, suggests that though the motivations for using video sites and traditional electronic media (like television) do not differ significantly (Haridakis \& Hanson, 2009), there is nonetheless a clear distinction. The motivation for using a video site is closer to the motivation for using interpersonal communication media, but it is less related to that of traditional media. This distinction may stem from cultural differences of the video site usage environment. It may also be possible to further deduce if the dissemination characteristics of video sites and the characteristics of interpersonal communication are closer. These two queries merit further research in the future.

In relation to users' orientations towards innovation, this paper predicts that there will be a positive correlation between users' orientations towards innovation, and the level of usage involvement with the video site. However, the empirical results suggest the exact opposite. It is speculated that the lower level of involvement 
that is required of browsing may be in line with the inclination towards risk-taking or the desire to try new experiences, among other characteristics. On the other hand, a higher level of involvement requires profound thinking when participating, or more time, skill, and patience are needed for production. As such, this cannot be explained simply by the orientation towards innovation. However, in terms of when the users start using video sites, it is confirmed that the earlier video sites are used, the level of involvement is indeed higher.

In terms of demographics, it was found that the level of involvement for the genders do not differ much. This is in stark contrast with the impressions of gender differences stated by the majority of research on the Internet. This paper argues that videos sites are a product of Web 2.0. If videos sites are compared to other communication platforms on the Internet of an earlier period, they are technologically less sophisticated and more interactive media. Video-sharing sites emphasize users' participation and collective knowledge. Even if the content-making requires more expertise, such as shooting or editing software knowledge in film-making, with the proliferation of numerous digital video technologies into household appliances, and the simplification of equipment and software, the stereotypical impressions of the gender difference in computer literacy, at least in relation to video sites, may no longer exist. However, the Internet population has been ushered into the age of heterogeneity. The variables of the demographics of past Internet research may have to be considered more meticulously in the future.

In conclusion, this paper confirms that the greater the level of usage involvement, the higher the level of gratification obtained from video-sharing sites. From past findings on gratification of Internet usage, the sum of all the predictor variables often does not exceed 10 percent (LaRose \& Eastin, 2004). However, all these variables in this study on the degree of involvement after adjustment, is $\mathrm{R}^{2}=.974$. Therefore, this paper extends and furthers existing research through the integration of Uses and Gratifications and Diffusions of Innovation theories.

This study has its limitation because it only conducts surveys and interviews in a single country, thus the findings may have cultural differences when generalizing to other regions of the world. In addition, this study does not apply more advanced statistical methods due to nominal and ordinal natures of some variables.

Future research can base on this article and further statistical models to add to the theoretical foundations of communication behaviors on video-sharing sites.

\section{Note}

In total, Taiwan’s donation to the earthquake amounted to approximately NT \$5.9 billion (about \$205 million) and topped the world's total contribution (Ko, 2001) https://www.youtube.com/watch?v=MltKxmQpB2A.

\section{References}

Baumer, E., Sueyoshi, M., \& Tomlinson, B. (2008). Exploring the Role of the Reader in the Activity of Blogging. In M. Czerwinski, \& D. S. Lund (Chair), Shared Authoring. Meeting of Proceedings of the 2008 Conference on Human Factors in Computing Systems (CHI, 2008), Florence, 9 April 2008, 1111-1120.

Broos, A., \& Roe, K. (2006). The Digital Divide in the Playstation Generation: Self-Efficacy, Locus of Control and ICT Adoption among Adolescents. Poetics, 34, 306-317. http://dx.doi.org/10.1016/j.poetic.2006.05.002

Bruns, A. (2008). Blogs, Wikipedia, Second Life, and beyond: From Production to Produsage. Digital Formations, 45. NY: Peter Lang.

Busselle, R., Reagan, J., Pinkleton, B., \& Jackson, K. (1999). Factors Affecting Internet Use in Asaturated-Access Population. Telematics \& Informatics, 16, 45-68. http://dx.doi.org/10.1016/S0736-5853(99)00018-0

Charney, T., \& Greenberg, B. (2002). Uses and Gratifications of the Internet. In C. Lin, \& D. Atkin (Eds.), Communication, Technology and Society: New Media Adoption and Uses (pp. 379-407). New York: Hampton Press.

Chen, C. P. (2009). Exploring Interpersonal Communication and Self-Presentation of Users on YouTube. National Science Council Project Reports, Taoyuan: Yuan Ze University.

Chen, H. T. (2008). Understanding Content Consumers and Content Creators in the Web 2.0 Era: A Case Study of YouTube Users. Annual Meeting of the International Communication Association, Montreal, 22 May 2008, 11. http://citation.allacademic.com/meta/p_mla_apa_research_citation/2/3/3/7/0/p233709_index.html

Courtois, C., Mechant, P., Marez, L., \& Verleye, G. (2009). Gratifications and Seeding Behavior of Online Adolescents. Journal of Computer-Mediated Communication, 15, 109-137. http://dx.doi.org/10.1111/j.1083-6101.2009.01496.x

Dutton, W. H., Rogers, E. M., \& Jun, S. (1987). Diffusion and Social Impacts of Personal Computers. Communication Re- 
search, 14, 219-250. http://dx.doi.org/10.1177/009365087014002005

Ebersole, S. (2000). Uses and Gratifications of the Web among Students. Journal of Computer-Mediated Communication, 6. http://jcmc.indiana.edu/vol6/issue1/ebersole.html

Fernando, A. (2007). Social Media Change the Rules. Communication World, 24, 9-10.

Goffman, E. (1959). The Presentation of Self in Everyday Life. New York: Doubleday.

Hanson, G., \& Haridakis, P. (2008). YouTube Users Watching and Sharing the News: A Uses and Gratifications Approach. Journal of Electronic Publishing, 11, 6. http://dx.doi.org/10.3998/3336451.0011.305

Haridakis, P., \& Hanson, G. (2009). Social Interaction and Co-Viewing with YouTube: Blending Mass Communication Reception and Social Connection. Journal of Broadcasting \& Electronic Media, 53, 317-335. http://dx.doi.org/10.1080/08838150902908270

Harp, H., \& Tremayne, M. (2007). Programmed by the People: The Intersection of Political Communication and the YouTube Generation. Annual Meeting of the International Communication Association, San Francisco, 23 May 2007, 11-16. http://citation.allacademic.com/meta/p_mla_apa_research_citation/1/7/3/0/6/p173067_index.html

Hsiao, M. C. (1998). An Exploratory Study of Taiwan College Students' Internet Using Behaviors, Motivations, Gratification Levels, and Internet Addiction. Master's Thesis, Hsinchu: Department of Communication, Chiao-Tung University.

Huang, C. Y., Shen, Y. Z., Lin, H. X., \& Chang, S. S. (2007). Bloggers' Motivations and Behaviors: A Model. Journal of Advertising Research, 47, 472-484. http://dx.doi.org/10.2501/S0021849907070493

InsightXplorer (2009). Internet Usage in Taiwan: A Basic Investigation in December 2009. http://www.insightxplorer.com/specialtopic/crossmedia_200912.html

iSURVEY (2010). E-ICP 2010 Professional Electronic Yearbook of Full Products. Taipei: ISURVEY.

Kao, N. Y. (2006). Uses and Gratifications Theory on Web 2.0 Application-A Case of Online Video Sharing Websites. Master's Thesis, Taipei: National Taiwan University of Science and Technology.

Katz, E., Blumler, J. G., \& Gurevitch, M. (1974). Utilization of Mass Communication by the Individual. In J. G. Blumler, \& E. Katz (Eds.), The Uses of Mass Communications: Current Perspectives on Gratifications Research (pp. 19-31). Beverly Hills: Sage Publications.

Katz, E., Gurevitc, M., \& Haas, H. (1973). Use of Mass Media for Important Things. American Sociological Review, 38, 164-181. http://dx.doi.org/10.2307/2094393

Kaye, B. K. (1998). Uses and Gratifications of the World Wide Web: From Couch Potato to Web Potato. New Jersey Journal of Communication, 6, 21-40. http://dx.doi.org/10.1080/15456879809367333

Kaye, B. K. (2005). It’s a Blog, Blog, Blog World: Users and Uses of Weblogs. Atlantic Journal of Communication, 13, 73-95. http://dx.doi.org/10.1207/s15456889ajc1302_2

Ko, S. L. (2011). Intricate Bonds behind Taiwan’s Donations to Japan. Kyodo News, May 26.

LaRose, R., \& Eastin, M. (2004). A Social Cognitive Explanation of Internet Uses and Gratifications: Toward a New Model of Media Attendance. Journal of Broadcasting and Electronic Media, 48, 358-377. http://dx.doi.org/10.1207/s15506878jobem4803_2

Leary, M. R., \& Kowalski, R. M. (1990). Impression Management: A Literature Review and Two-Component Model. Psychology Bulletin, 107, 34-47.

Lee, F. C. (2008). The Motivations and Identification of New Internet Media Users-A Case Study of Video Blog. Master's Thesis, Taipei: Chinese Culture University.

Li, S. S. (2003). Electronic Newspaper and Its Adopters: Examining the Factors Influencing the Adoption of Electronic Newspaper in Taiwan. Telematics and Informatics, 20, 35-49. http://dx.doi.org/10.1016/S0736-5853(02)00002-3

Livingstone, S., \& Bober, M. (2005). UK Children Go Online. London: Economic and Social Research Council.

McKinney, V., Yoon, K., \& Zahedi, F. M. (2002). The Measurement of Web-Customer Satisfaction: An Expect Ion and Disconfirmation Approach. Information Systems Research, 13, 296-315. http://dx.doi.org/10.1287/isre.13.3.296.76

Melone, N. P. (1989). A Theoretical Assessment of the User Satisfaction Construct in Information Systems Research. Management Science, 36, 76-91. http://dx.doi.org/10.1287/mnsc.36.1.76

Morris, M., \& Ogan, C. (1996). The Internet as a Mass Medium. Journal of Communication, 46, 39-50. http://dx.doi.org/10.1111/j.1460-2466.1996.tb01460.x

Oh, J. H., Susarla, A., \& Tan, Y. (2008). Examining the Diffusion of User-Generated Content in Online Social Networks. Mimeo, Seattle, WA: University of Washington.

Örnebring, H. (2008). The Consumer as Producer of What? User-Generated Tabloid Content in The Sun (UK) and Aftonbladet (Sweden). Journalism Studies, 9, 771-785. 
Papacharissi, Z., \& Rubin, A. M. (2000). Predictors of Internet Use. Journal of Broadcasting \& Electronic Media, 44, 175196. http://dx.doi.org/10.1207/s15506878jobem4402_2

Peter, J., \& Valkenburg, P. M. (2006). Adolescents’ Internet Use: Testing the “Disappearing Digital Divide” versus the “Emerging Digital Differentiation” Approach. Poetics, 34, 293-305. http://dx.doi.org/10.1016/j.poetic.2006.05.005

Rogers, E. M. (1983). Diffusion of Innovations. New York: Free Press.

Schlenker, B. R., \& Wowra, S. A. (2003). Carryover Effects of Feeling Socially Transparent or Impenetrable on Strategic Self-Presentation. Journal of Personality and Social Psychology, 85, 871-880.

http://dx.doi.org/10.1037/0022-3514.85.5.871

Shao, G. (2009). Understanding the Appeal of User-Generated Media: A Uses and Gratification Perspective. Internet Research, 19, 7-25. http://dx.doi.org/10.1108/10662240910927795

Song, I., LaRose, R., Eastin, M. S., \& Lin, C. (2004). Internet Gratification and Internet Addiction: On the Uses and Abuses of New Media. CyberPsychology \& Behavior, 7, 384-394. http://dx.doi.org/10.1089/cpb.2004.7.384

Toffler, A. (1980). The Third Wave. New York: Bantam Books.

Tsai, C. R. (2007). The Study of User Gratification for Participators of Online Video Sharing Websites. Master's Thesis, Taipei: National Taiwan Normal University.

Tsai, P. R., Tsai, C. C., Xie, T., \& Chen, J. J. (2006). The Factors Affecting Students' Use of Video Blog in Taipei. Master Thesis, Taipei: National Taiwan University of Arts.

Walther, J. B., \& Burgoon, J. K. (1992). Relational Communication in Computer Mediated Interaction. Human Communication Research, 19, 50-88. http://dx.doi.org/10.1111/j.1468-2958.1992.tb00295.x

Wolfradt, U., \& Doll, J. (2001). Motives of Adolescents to Use the Internet as a Function of Personality Traits, Personal and Social Factors. Journal of Educational Computing Research, 24, 13-27.

http://dx.doi.org/10.2190/ANPM-LN97-AUT2-D2EJ

Yang, C., Hsu, Y. C., \& Tan, S. (2010). Predicting the Determinants of Users’ Intentions for Using YouTube to Share Video: Moderating Gender Effects. Cyberpsychology, Behavior and Social Networking, 13, 141-152. http://dx.doi.org/10.1089/cyber.2009.0105

Ye, J. S. (2007). The Study of Service Quality and Gratification of Audio Video Web-Use YouTube and Noname Blog as Examples. Master Thesis, Taipei: Chinese Culture University. 
Scientific Research Publishing (SCIRP) is one of the largest Open Access journal publishers. It is currently publishing more than 200 open access, online, peer-reviewed journals covering a wide range of academic disciplines. SCIRP serves the worldwide academic communities and contributes to the progress and application of science with its publication.

Other selected journals from SCIRP are listed as below. Submit your manuscript to us via either submit@scirp.org or Online Submission Portal.
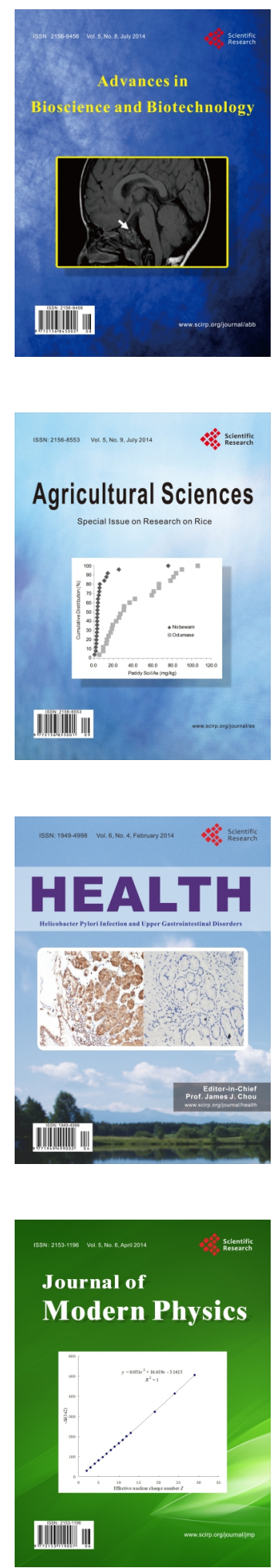
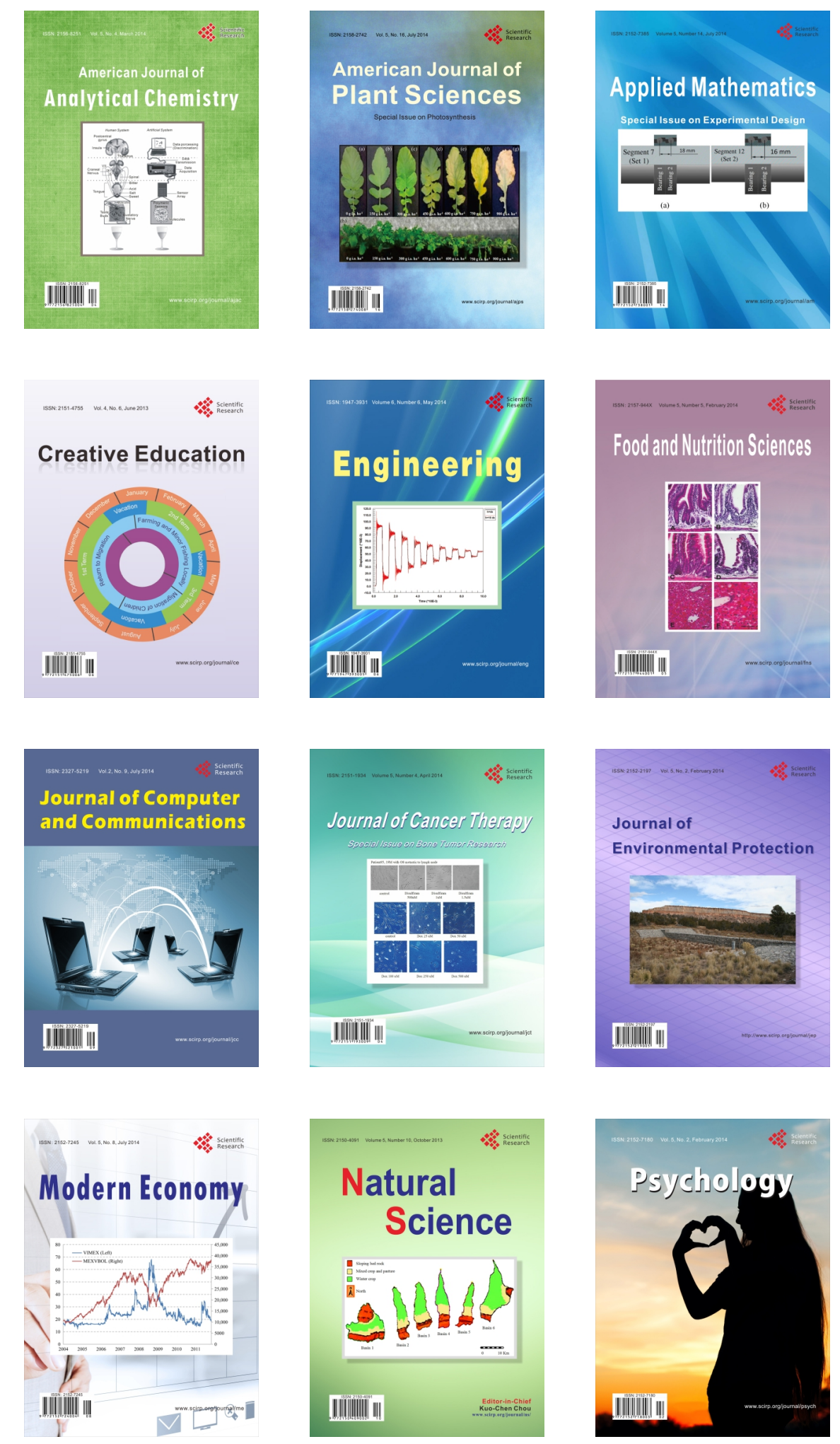